\title{
Study on the Inheritance and Development of Chinese Pewter Art in Malaysia
}

\author{
Xiaochen Geng \\ Postdoctoral research station \\ Nanjing Normal University \\ Nanjing, China 210000 \\ Xiamen Academy of Arts and Design \\ Fuzhou University \\ Xiamen, China 361000
}

\begin{abstract}
This article through the study about the development situation of Malaysian Pewter, analyze Malaysian Pewter artistic features while combing their plastic arts features, and then make further analysis of the relationship between Malaysia Pewter and Chinese Pewter in order to explore the influence of Chinese Pewter art to Malaysia Pewter.
\end{abstract}

Keywords-China; Malaysia; Pewter appliance; inheritance and development

\section{INTRODUCTION}

The development of Pewter in the world has a long history, there are Pewter production and use in many countries in Europe, America and Asia. In Malaysia of Asia, because of it has many Pewter mines, so it has geopolitical advantage to obtain Pewter raw materials, now Malaysia Pewter has a certain influence in the world, especially their "Royal Selangor" Pewter brand is widely known at home and abroad, it is currently the world's most famous Pewter brand.

And Pewter production and use in China also has a long history, China's Pewter through the development of different times, there have been breakthroughs and innovations in types and plastic arts, but overall, China's Pewter art in the overall artistic style presents simple and elegant features.

Though after the development of different times, Malaysia Pewter has now developed a diversity feature, but because of the influence from economic, social, historical, transportation and other factors, we can still see the impact of Chinese Pewter from modern and contemporary Malaysia Pewter designs.

\section{DEVELOPMENT AND ARTISTIC FEATURES OF MALAYSIAN PEWTER}

Malaysia's Pewter production had ranked first in the world

2015,China Postdoctoral Science Foundation, Research about the Radiation and Inheritance of Chinese Pewter art in Southeast Asia, number: 2015M570465, initial results

2014, China National Social Science Foundation Art Project, Research of Chinese Pewter craft culture and its artistic active state inheritance, project number: 2014CG03413, initial results

2015, high-level "211" Engineering University Project, Fuzhou University Art Theory discipline support program, initial results

2014, University-level subject in Fuzhou University, Research about the plastic arts and technical study of Fujian Pewter, Item Number: 14skf92 Final result before the 1970s, after that Malaysia's Pewter production has been the leading position in the world for a long time, therefore Malaysia is known as "the country of Pewter". In Malaysia Pewter metal which occupies a very important position and it is called "national treasure"by Malaysians. Malaysians take it very seriously for the development and utilization of the important resource with geographic advantage. Pewter which produced by the Malaysian have high quality, its Pewter normally with Pewter content up to $97 \%$. Good material together with the international design and precision production, Malaysian Pewter become famous soon.

There are mainly two Pewter factories currently in Kuala Lumpur, Malaysia, the most famous one is the "Royal Selangor" Pewter factory which established in 1885, "Royal Selangor" is now the most famous Pewter brand in Malaysia, its original brand name is "Selangor", as favored by the royal so it was conferred the "Royal Selangor" name, and now it has developed into the biggest Pewter factory in the world. Early period "Selangor" mainly produced censer, candlesticks and other traditional Pewter products for Asian markets ; in the British colonial period, it extended Pewter species to all kinds of ashtrays, beer equipments, wine cups, etc; then as the times development and the popularity of modernist style in the world, Royal Selangor also integrated modern design concepts into Pewter production, developed and designed many moderniststyle Pewter,which gave new forms and contents for Pewter in both appearance and connotation, and gradually expand the Pewter market to Europe, America and other places; its sales target change from serve for individuals or families at early time into a broader group market, some sports teams and museums from other countries now will order customized trophies and other products from them. Another Pewter factory in Kuala Lumpur is Tumaske Co. Ltd, they also produce various kinds of Pewter metal products, including a variety of practical products and decorative items, its product types ware less than "Royal Selangor". But its overall style is as "Royal Selangor", the above three artistic styles in different periods all under production now. 


\section{ThE DEVElopment AND ARTISTIC FEATURES OF CHINESE PEWTER IN DIFFERENT PERIODS}

Pewter production and use in China also has a long history, which can be proved by the relevant archaeological excavations, "from the unearthed a large number of high-tin bronze ware and coated Pewter on bronze helmet from Yin $\mathrm{Xu}$ in Anyang,Henan,China, we can see that the people at that time was able to smelting Pewter and used in metallurgy and production", from which we can see that "China no later than the late Shang Dynasty has already produced purely Pewter metals and Pewter products".

Since then, China's Pewter through the development of different times, there have been breakthroughs and innovations in types and plastic arts. Due to various reasons, there are extremely few Pewter products before Ming and Qing Dynasties which discovered in archaeological process. To the Ming Dynasty, the use of Pewter metal had corresponding changes, the use of Pewter was not limited by social status at that time, so Pewter products became available to common people, from some of the masterpieces of Pewter products, we can also see that until Ming Dynasty, Pewter had made significant breakthrough. Such as the Pewter made Wu Gong which collected in Pewter museum of Gejiu in Yunnan province, the whole design is simple and unadorned,is the typical type in Ming Dynasty. In Ming Dynasty, Pewter category also increased over the previous time, there were many new varieties such as Pewter inlay products; Meanwhile, Pewter was also widely extended to the literati's writing accoutrements such as the Pewter ink pool and Pewter water droplet mentioned in"Wan Shu Za Ji".

Early to mid-Qing Dynasty, the one with the most artistic features should be literary Pewter tea set. Literary Pewter tea set had a further development based on inheritance of the Ming Dynasty achievements. At that time emerged a number of Pewter product craftsmen and masters with high artistic culture, they had made some new breakthroughs in the material, technology and decoration process of Pewter pot production. Such like Shen Cunzhou, Lu Kuisheng, Zhu Jian and so on. Shen Cunzhou was good at making all kinds of Pewter pot, he accurately grasped the pot shape, his Pewter pot with water silver color patina lie a mirror, the carved verses,names and printings were all structured well; Lu Kuisheng was famous for his lacquer-ware, he had great innovation sense, he used Pewter as pot carcass, outside use lacquer for pot shape,and first created the lacquer pot with Pewter carcass; The Pewter products made by Zhu Jian also extremely fine, such as the Imperial Palace had a plum Pewter pot made by him, the pot mouse is square, pot belly is round, pot handles and buttons are all inlaid jade, on the pot body carved with plum image, beside plum it carved the verse"An Xiang Fu Dong", signed with Zhu Shimei "Fig. 1".

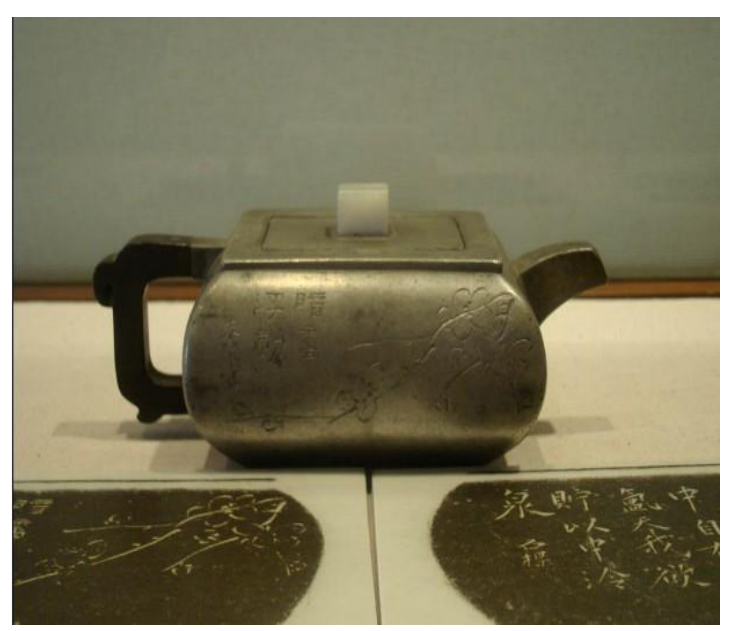

Fig. 1. Zhu Jian Pewter pot in Beijing Palace Museum

After the Qing Dynasty, Pewter shape from the design point of view gained more freedom, with the rapid development of modern industry, Chinese Traditional Pewter production industry as "old business" gradually in line with the times, and emerged modern industrial Pewter products based on the development of technology. In modern society, there are a lot of Pewter metals been produced into Pewter products through modern industry or traditional manual method, according to the application they could be divided into two categories, one is a variety of decorative arts and crafts such as: Pewter plate, Pewter coins, Pewter reliefs, Pewter trophies, Pewter vases and so on,this category products use Pewter's features of not easy to oxidize and change color, beautiful silver color and good texture, while the price only be ninth of silver, so Pewter products can be described as high quality with cheap price; the other category is the tea set,wine set and others which have both practical and decorative value.

\section{The RADiATION AND INFLUENCE Of ChINESE PEWTER TO MALAYSIAN PEWTER}

Pewter production exists as ancient craft is not always exist in isolation, the same arts and crafts all over the world will influence each other by the a variety of communications between them. There is an inextricably linked between China and Malaysia Pewter, which prominently expressed in the communications of social and historical reasons, transportation, economic exchanges and participation in various joint activities.

\section{A. The Chinese Dominated the Raw Material Mining and the Production of Pewter}

Malaysia has rich Pewter mine resources, in early times the discovery and mining of Pewter metal was called "black gold mining". A hundred years ago, many Chinese go to Malaysia and earned a living by "Black god mining"; moreover start from the mid eighteenth century, the money and companies invested by Chinese businessmen also contributed to the development of Malaysian Pewter mining. "Chinese people have the concept of business organization, which makes them have more advantages than Malaysians", so under Chinese efforts they made Malaysia rapid rise to the world's number 
one country of Pewter production amount. Above mentioned "Royal Selangor" brand which still owns high reputation in Malaysia and even the whole world was originally established by a Chinese people who come from Shantou, Guangdong. After 120 years the brand in the world still comes out on top among the same industry. The Pewter industry which dominated by the Chinese is bound to integrate many traditional Chinese culture in them.

\section{B. The Development and Innovation of Chinese Pewter in Malaysia}

1) The inheritance of Chinese traditional Pewter shapes and decorations: There are mainly two categories for Chinese Pewter shapes, one is the shape for practical product, another category is the sacrificial vessels and decorations related to people's spiritual life. The practical products include pan, kettle, bowl, plate, dish, spoon, chopsticks, pot, Zhu, Diao, cup, cup holder, handleless cup, can, box, Bi Cha, bottle, urn, basin, pail, pillow, saliva pot, hot-water bottle, Xi $\mathrm{Hu} \mathrm{zi}$, lighting appliances, as well as study appliances such as penholder, pen inserter, ink cartridge, water jet, ink stone, paperweight, water pool, ink pool; non-practical Pewter products mainly related with people's spiritual life, such as sacrificial vessels for religious worship and other ceremonies like Wu Gong,Ding, Fu, Gui, Zun, Jue, Yi Wei and others; non-practical Pewter products also include decorations and musical instruments which for people to pursue fashion or life interests.

"Royal Selangor" was the most representative Pewter products in Malaysia from its Pewter category, most of them also not able to escape from Chinese traditional Pewter category, it mainly divided into practical and non-practical products two categories. "Royal Selangor" brand is a family business, its founder Mr. Yang Kun was a Chinese, his handmade pumpkin Pewter pot now still is the unique treasure of "Royal Selangor" brand, its pumpkin shape is a typical style of Chinese Pewter products "Fig. 2"; "Royal Selangor" targeted Chinese market in its early development period, so it borrowed heavily from Chinese traditional Pewter shapes such like use the traditional round lid and square body shape. From the current market, Malaysia's Pewter products mainly are modern industrial products, it focus on practicality of the Pewter products and also focus on international style creation. It has a lot of Pewter production categories, including traditional wine cup, tea set, censer, candle holder, picture frame, vase, ornaments and other categories,other than that it also developed a number of people daily used U disk, game characters, a variety of objects affiliated decorations, all kinds of stationery and so on. In "Royal Selangor", Pewter product category made new breakthroughs due to the development of times on the basis of traditional Chinese Pewter categories.

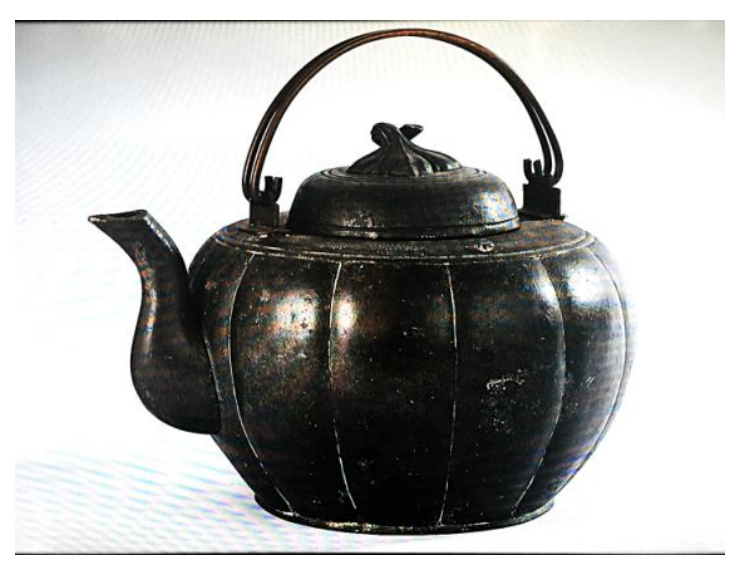

Fig. 2. Pewter pot designed by the "Royal Selangor" founder Mr. Yang Kun. (Picture source: Author shot in Malaysia "Royal Selangor" Pewter factory)

In addition, Chinese traditional Pewter normally with a variety of decorative patterns, these patterns include animal patterns, plant patterns, geometric patterns, text symbol patterns "Fig. 3", and some other patters about life scenes, myths and legends, folk tales, etc. We can find many Chinese traditional patterns from the "Royal Selangor" Pewter decorations, such as carved animal patterns, plant patterns and text symbols on all kinds of Pewter products.

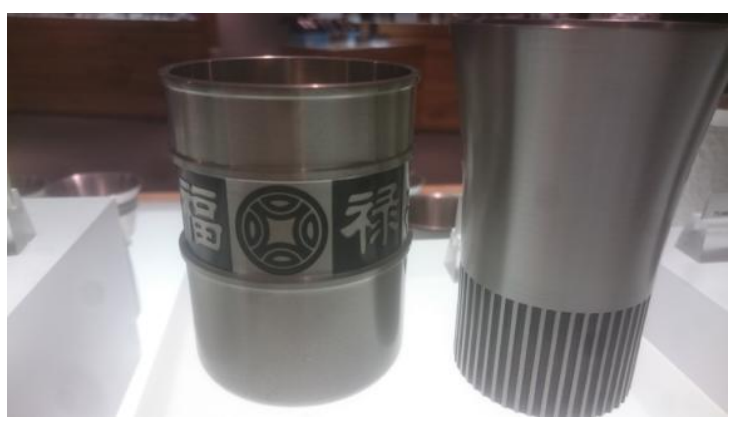

Fig. 3. The text symbol on tea pot of "Royal Selangor" (Picture source: Author shot in Malaysia "Royal Selangor" Pewter factory)

2) The inheritance of Chinese traditional Pewter craft: Production of Pewter products is a traditional skill popular in our country folk, it is often referred as "Da $\mathrm{Xi}$ ", which is a tskill with certain technical content, in the production process it requires the use of various essential tools, and has its own specific production process. China's traditional Pewter production equipment mainly are crucible, smelting furnace, iron table, Cai Ban, polishing equipment, measure and cutting tools, welding and grinding tools, module, Zhendun tools, forging tools and chisel, flower chisel, brush, writing brush and other auxiliary tools; our traditional Pewter craft also has a complete and complex production process, the entire production process are: melting, pouring plate, cutting, shaping, scraping, welding, decoration, polishing and carving. Every process of traditional Pewter production has its own unique arts and crafts, and each craft is closely linked with the craft of next process, process and craft closely linked, the 
perfect cooperation with every process so to ultimately exhibit artistic products.

Malaysia "Royal Selangor" Pewter products although now use industrialized production methods in some production process due to the development of the times, but in many tools use and process still not able to escape from Chinese traditional Pewter production process, such as melting, casting plate, cutting, shaping, scraping "Fig. 4", welding, decoration, polishing and craving processes still followed the tradition, beating the patterns on the surface still need man use hammer and so on.Overall speaking, semi-industrial production of Malaysian Pewter products improved the production efficiency of traditional Pewter products, is the development based on traditional Chinese Pewter production industry.

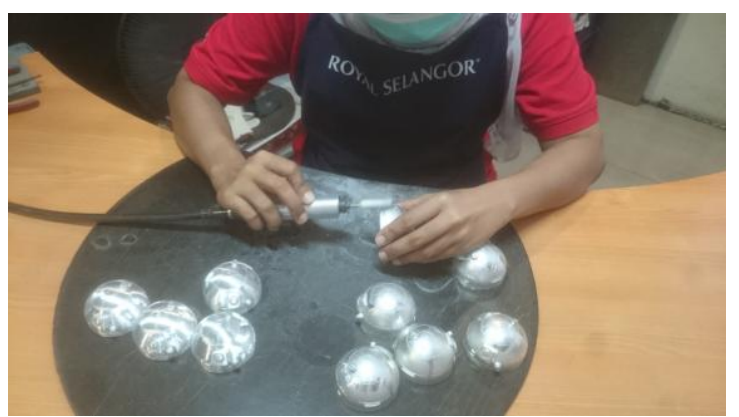

Fig. 4. Scraping and Polishing process in Pewter production of "Royal Selangor" (Picture source:Author shot in Malaysia "Royal Selangor" Pewter factory)

\section{CONCLUSION}

From the analysis in this paper,Malaysia has China on its south side, Malacca has always been the inevitable pass for China to the world, its friendly exchanges with China has a long history, mutual flow of Chinese and foreign goods trade exchanges and participation in various joint activities, and special historical reasons all make the inextricably relationship between the Pewter of China and Southeast Asia, which has indicated from Pewter raw materials, production processes, modeling and decorations of both countries' Pewter products. Today, with the continuous development of bilateral economic and social progress, the traditional process with each other has more space for learning and improving. Especially the Malaysian Pewter products which already impacted by Chinese Pewter products,now it is already world famous and has been developed to the stage of industrialization, we can draw useful development experience from their growth,and implement the inheritance and development of traditional Chinese Pewter art.

\section{REFERENCES}

[1] "Encyclopedia of Chinese tea set" Wang Jianrong, Zhao Yanyan, Guo Danying. Shandong Science and Technology Press, 2008

[2] "Dynasty anecdotes compilation" Zhang Shouyong, Qing Dynasty, Guangxu Realistic Press

[3] "Art Research of Chinese Pewter products", Geng Xiaochen, Suzhou University Doctoral Dissertation, 2013

[4] "History of Ancient Chinese industry" Zhu Cishou. Shanghai: Xue Lin Press 1988
[5] "History of Malaysia", Barbara Watson Andaya, Leonard Andaya. China Publishing Group, China Encyclopedia Publishing company 2010

[6] "Discussion on China's Early (except bronze and iron) Metal Craft" in "Archaeological News" 2nd 1996. 